\title{
A Balancing Act? Inter-Ministerial Co-operation in the Work of the Cultural Attachés
}

\author{
Dimitra Kizlari| ORCID: 0000-0001-7298-6049 \\ Institute for Sustainable Heritage, University College London, London, UK \\ dimitra.kizlari.15@ucl.ac.uk \\ Domenico Valenza | ORCID: 0000-0002-6818-2790 \\ United Nations University-Institute of Comparative Regional Integration \\ Studies, Bruges, Belgium; Ghent Institute for International and European \\ Studies, Ghent University, Ghent, Belgium \\ dvalenza@cris.unu.edu
}

Received: 25 August 2020; revised: 25 November 2020; accepted: 5 May 2021

\section{Summary}

To date, the role of cultural attachés in foreign policy has not been the subject of scholarly research, despite the sharp rise in interest in the field of cultural diplomacy. The present study is a comparative analysis seeking to map the ecosystem in which cultural attachés are embedded with the aim to develop a first-time narrative about their role. Interviews with practitioners from Italy, The Netherlands and Sweden indicate that the post of the cultural attache is a field of responsibility primarily for two state actors. The Ministry of Foreign Affairs and the Ministry of Culture both have a vested interest in the work of these cultural operators. The findings suggest that there are two distinct organisational models in how Ministries of Foreign Affairs and Ministries of Culture co-exist and interact.

\section{Keywords}

cultural diplomacy - international cultural relations - foreign policy - cultural policy cultural attachés - soft power 
In the past two decades, new avenues for managing global communications have been on the rise and people-to-people exchanges are now at the heart of diplomatic activity. These new conditions pose significant challenges to the integrity of the diplomatic profession, which has largely remained stable over the course of more than 200 years. $^{2}$ In this changing landscape, our research shifts the emphasis away from the traditional fields of diplomatic activity (security, trade and defence) to focus on cultural diplomacy. Building on scholarship that analyses the role of cultural institutes comparatively, ${ }^{3}$ the article examines the policies and practices of three European countries with regard to the work of their cultural attachés.

The relationship of cultural attachés to two state organs, the Ministry of Foreign Affairs (MFA) and the Ministry of Culture (MoC), is the focus of this study. ${ }^{4}$ What we originally identified as competing policy portfolios that were trying to carve distinct regulatory spaces turned out to be a much more nuanced affair, with collaborative practices happening more often than previously thought. Hence, the research focused on understanding how co-operation between the two ministries takes places and, where this is not the case, what the reasons may be. In this study we have selected to work with three country cases (Italy, the Netherlands and Sweden) to research co-operation models between MFAs and MoCs with specific references to the work of the cultural attachés. The project attempts to create a narrative about the role, responsibilities and impact of cultural attachés to their countries' overall foreign policy strategy.

As countries increasingly attempt to push their national language and culture to the world's stage, more attention ought to be given to the modernisation of the diplomatic network to enable cultural attachés to respond and adapt to this fast-paced changing environment. Moreover, since the present study focuses on three Member States of the European Union, we believe that the

1 This research was conducted between May 2019 and August 2020. The authors declare that during the process there was no conflict of interest. The authors would like to express their gratitude to the anonymous reviewers of this manuscript for their feedback and to our interview participants who made this study possible. Sincere thanks should also go to Dr Maria Shehade for her thoughtful input.

2 Bjola and Kornprobst 2018; Constantinou, Cornago and McConnell 2016.

3 Carta and Badillo 2020; European Parliament 2016; Pamment 2012; Wyszomirski, Burgess and Peila 2003.

4 Although the official name of each ministry may differ from country to country, for reasons of brevity we will refer to the two state agents through their acronyms for the remainder of the text. Where we share direct quotes from the interview participants, the names will appear as they were originally quoted. 
lessons learned will also prove useful at the supranational level. The European Commission and the High Representative have developed a strategic approach to EU international cultural relations, ${ }^{5}$ to which the national cultural institutes have greatly contributed. ${ }^{6}$ The findings of this study will help to shed light on existing co-operation models and unveil potential underlying dynamics in EU Member States' cultural diplomacy strategies with a view to inform the approach of EU policymakers.

\section{The Ecosystem of Cultural Diplomacy: Theoretical and Analytical Perspectives}

The term 'cultural diplomacy' has been buzzing around for a few decades in academia and policy circles, yet its contours remain ambiguous. Compared with other intersecting terms such as soft power or public diplomacy, ${ }^{7}$ cultural diplomacy does not have a distinctive conceptual parent. Existing scholarship defines cultural diplomacy as a governmental practice that seeks to deploy culture in support of foreign policy objectives in order to build mutual understanding. ${ }^{8}$ Cultural diplomacy is also considered to be a subset or a dimension of public diplomacy, although it has been acknowledged that a clear-cut distinction between the two practices is difficult. ${ }^{9}$

The existing literature lacks information on the role and status of cultural attachés. Assumptions about the nature of their work have long held that they deal with the 'soft' aspects of cross-cultural communication. This parlance has rendered the post of the cultural attaché an ambiguous career choice among civil servants. Compared with their peers placed in trade or defence posts, cultural attachés do not enjoy equal status within ambassadorial settings as their portfolio has traditionally been regarded as a field of 'low politics.' ${ }^{10}$ This situation is exacerbated by the fact that the arts are ordinarily assigned small budgets by governments despite the much-lauded results they are said to yield." Moreover, the difficulty of attributing specific outcomes to cultural actions has made legislators sceptical about the usefulness of cultural projects beyond the domestic sphere where the organisational costs are higher and the challenge to convey the 'right' message is greater.

\footnotetext{
$5 \quad$ European Commission and High Representative 2016.

6 Carta and Higgott 2O2O; Helly and Valenza 2O2O, 3; Valenza 2O21, 344.

$7 \quad$ Nye 199o, 166; Cull 20o9, 19.

8 Cummings 2003, 1; Mark 2009, 1.

$9 \quad$ Ang, Isar and Mar 2015, 366.

10 Gould-Davies 2003, 193.

11 Gray and Wingfield 2011, 590-591.
} 
Historically, cultural attachés have been placed under the jurisdiction of the MFA. They are traditionally either diplomats of low diplomatic rank or support non-diplomatic staff who are assigned a cultural portfolio. ${ }^{12}$ In the past, the role was often given to ex-scholars with subjects such as anthropology, history, arts, linguistics and political science topping the list of preferred academic specialisms. ${ }^{13}$ What is interesting in the early writings dedicated to the subject is that the personal character of these agents seemed to matter more than their actual skillset or former job experience. A certain mythology has been built around the personality of the jobholder which sees the cultural attaché as a rather 'urbane character', a figure who embodies the very values they wish to communicate. ${ }^{14}$ This is a fascinating, yet slightly romanticised, depiction of the persona of the cultural attaché which brings the jobholder at odds with the more 'procedural' embassy system.

The post of the cultural attaché seldom stood independently and was often hosted in the press office while recently it is most often found within the public diplomacy section of the embassy. ${ }^{15}$ Perhaps seemingly a fitting solution to the financial constraints many governments face, embedding the cultural function within the embassy setting has been seen as controversial by cultural operators who generally prefer partnering with agents not directly linked to the government apparatus. ${ }^{16}$ Indeed, it has been noted elsewhere in the literature that operating through the diplomatic mission may not be a suitable choice in what Mangset has colloquially called the 'embassy ghetto'. ${ }^{17}$

Interestingly, of the countries that first sought to establish a cultural presence abroad in the 2oth century, the most common model of representation, as well as the costliest, has been that of the cultural institute. The cultural institutes were designed as independent or semi-autonomous institutions in order to remove any hint of political influence from the cultural and educational work they undertook. Bestowed with generous budgets, the institutes were markers of national wealth and power and they exerted influence abroad through language lessons, lectures, exhibitions and film screenings, among other activities. ${ }^{18}$ France, Italy, Germany and the UK have been the dominant players in this ecosystem, accounting today for more than two-thirds of the

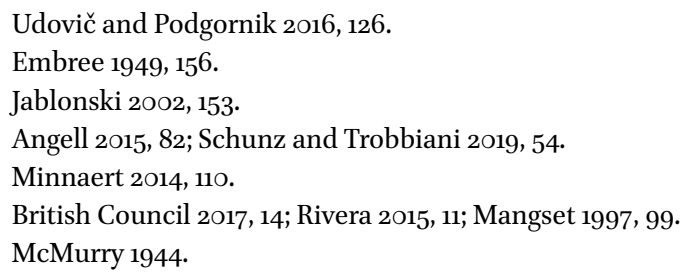


global network of cultural institutes. ${ }^{19}$ Opposed to that paradigm stood the more modest, and viable in terms of expenses, model of the cultural attaché installed within the diplomatic mission.

This distinction has not prevented mixed models from emerging either as temporary or permanent features of the promotional network. For example, in its early days, the then newly founded British Council trusted the diplomatic corps to run its operations until the administration of the Council decided to appoint 'special representatives overseas', gradually putting distance between its activities and the operation of the British embassies. ${ }^{20}$ What these power manoeuvres reveal is the need to understand how organisational struggles shape strategy, and ultimately, determine the imprint of cultural diplomacy. With the diplomatic landscape rapidly changing in the past century, new powers have emerged challenging the authority of the MFA as being the exclusive broker in building cross-cultural relations. Therefore, in what follows we aim to map for the first time the structural ecosystem in which cultural attachés are embedded.

\section{Methodology}

As the subject is under-researched, it has been a major challenge to locate and target system-bound models presenting significant divergence. This is important as the cases should always belong to the same system to allow for meaningful comparisons. ${ }^{21}$ We chose to mobilise our network of contacts within the cultural diplomacy field acquired from previous studies and use them as informal sources to single out non-divergent cases. It was important for us to choose cases whose cultural diplomacy strategies have reached a degree of organisational maturity to be able to reach sound conclusions on the preferred model of self-organisation. Therefore, we sought countries that have at least half a century of established cultural presence abroad. During these informal consultations, the example of Italy was set as the typical standard. Italy, like many other countries, has developed a network of attachés exclusively linked to the MFA. Next, the search focused on finding models that deviate from this standard, namely cases in which attachés maintain at least one established connection with a departmental authority other than the MFA. The examples

\footnotetext{
19 Paschalidis 2009, 286.

20 Donaldson 1984, 59.

21 Yin 2014, 27-70.
} 
of Sweden and the Netherlands soon emerged as divergent cases. In both countries, cultural attachés have formal links to the MFA as well as the MoC.

Reaching out to a network of already established contacts was important from another perspective as it allowed the snowballing of participants. Snowballing is a sampling method that uses chain-referrals; this means that the subjects under study choose prospective participants among their acquaintances. It is important to note that these are 'hard-to-reach' groups and access is not always guaranteed, hence, the value of snowballing. ${ }^{22}$ We conducted 26 interviews in total across the 3 cases, the majority of which with cultural attachés (see Appendix). In the Dutch and Swedish cases, a handful of interviews were with representatives from the ministries. In recruiting potential participants, we also tried to cover a variety of geographies to ensure that the sample is balanced in terms of the challenges the agents are facing on the ground. Last, due to the absence of studies on the subject, and thus the inability to triangulate information, it was decided that the participants would not only act as primary sources of information, but a small selected number would also be involved as reviewers. ${ }^{23}$ Six participants (two per country) were given a draft of their country case to review in order to ensure that the content of this article reflects accurately the content of the interviews and the status quo in each country.

Diplomatic missions with a considerable number of staff are the most likely to appoint a cultural attaché since the post is usually regarded as a luxury. Ministries tend to maintain only a small number of such agents, who are placed in cities with a vibrant arts scene and multiple cultural operators. Such a rich cultural infrastructure is necessary for these professionals, as their job portfolio is incredibly varied. It spans from organising literary translations and artistic exchanges to brokering exhibitions and hosting film features among several other functions of the creative spectrum. Tasks vary depending on local needs and reporting impact seems to be increasingly important.

In the following pages, the article will analyse the key features of three cases: Italy, the Netherlands and Sweden. Using the conceptual model of Kizlari and Fouseki, the authors will examine how the MFA and the MoC interact in five operational areas: (i) appointments, (ii) hierarchy, (iii) funding,

$22 \quad$ Noy $2008,336$.

23 Flick 2004, 179. 
(iv) agenda-setting, and (v) evaluation. ${ }^{24}$ Kizlari and Fouseki's work shows that material practices are interwoven with discourses and that strategic intentions always find a material expression. Therefore, by studying these five structural components, we can study the intangible elements that characterise the system of administration of cultural diplomacy.

\subsection{The Case of Italy}

Italian Institutes of Culture (IICs) have played a pivotal role in Italy's foreign policy infrastructure since their emergence. Under the impetus of fascist intelligentsia, the Royal Decree no. 2179 of 19 December 1926 established the creation of an institute to 'spread Italian culture abroad and promote intellectual relationships with third countries'. ${ }^{25}$ Although the IIC's network reported to the MFA, the Royal Decree provided a mixed management model in respect of the appointment of directors. Under Article 5, the proposed directors had to be recognised as scholars of great repute and appointed by the MFA in agreement with the Ministry of Education (Ministero dell'Istruzione).

The end of the Second World War led to a fundamental rethinking of Italy's cultural diplomacy. This involved the adoption of several legal and policy documents, including the 195 o Statute of the Italian Cultural Institute abroad, which sought to expand the IIC's portfolio of activities and to promote reciprocal cultural relations with host countries. However, the new framework did not clarify the mandate or hiring process, nor it did provide the IIC's growing staff, including directors, attachés and teachers, with a defined career path. This legal vacuum gave the MFA extensive discretion, ${ }^{26}$ which kept relying on personnel from the Ministry of Education (notably for teaching staff). It was only in 1990 that the cultural promotion of personnel was granted an ad hoc employment status and portfolio as MFA's public servants in the area of cultural promotion. Under this legal framework, ${ }^{27}$ cultural attachés are appointed through centralised public competition for permanent positions, which is organised either by the MFA or by other central structures operating on its behalf. Contrary to competitions for a diplomatic career, which take place roughly every year, calls for cultural attachés are not published on a regular basis but are rather organised according to the MFA's needs. Since the number of qualified applicants far exceeds the total available positions, selection follows a three-step process, including multiple-choice tests, a written examination and an oral stage.

\footnotetext{
24 Kizlari and Fouseki 2018, 138.

25 Law n. 2179, 1926, emphasis added.

26 Ferri 2012, 53 .

27 Law n. 401, 199 .
} 
The whole selection process seeks to test the knowledge of candidates not only in the humanities (i.e. cultural heritage, theatre, literature) but also in administrative law and public accounting, as familiarity with these subjects is considered paramount for working as a public servant. An examination board supervises the selection process. The board is appointed by the MFA or the structure operating on its behalf and is composed of civil servants from the MFA and other ministries. ${ }^{28}$

As soon as the centralised recruitment process is completed, the new public servants are assigned to the offices of the Directorate General (DG) in charge of cultural relations or, in some cases, to other DGs or services of the Ministry. Recruits are provided with further training during this phase, specifically in the areas of administrative law and public accounting, with special emphasis on the activities of diplomatic missions. After an induction phase in Rome, public servants are allowed to apply for temporary positions abroad. Within the IIC's network, they can serve either as cultural attachés (addetto culturale), the second highest position of the institute, or as directors (direttore), based on seniority requirements. ${ }^{29}$ Although neither directors nor attachés are diplomats by profession, they hold a diplomatic passport and are part of the broader diplomatic mission.

In terms of hierarchy, the status of the IIC is a peculiar feature in Italy's cultural diplomacy. According to the law, institutes are granted full operational and financial autonomy. ${ }^{30}$ Cultural attachés report directly to the directors of the institute, while guidance and supervision duties (funzioni di indirizzo e vigilanza) on IIC activities are given to the local embassy or consulate. This double track solution combining autonomy and local oversight is seen as a highly beneficial solution that allows the IIC to adapt to the many challenges and opportunities of local contexts. For instance, a cultural attaché acknowledged that his high level of autonomy was envied by other European colleagues working in more centralised cultural institutes. At the same time, some observed that, whereas the IIC's autonomy increases attachés' flexibility, improved inter- (between Rome and the IICs) and intra-communication (between the IICs) would also be valuable to set up joint initiatives or share best practices. This also raises the question of the relation with the hierarchical superior. Cultural attachés tend to agree that guidance and supervision duties

28 In the competition released in 2018, a senior civil servant from the Ministry of Cultural Heritage and Activities was appointed to the Board as an expert for the areas of Cultural Heritage and Administrative Law (Commissione RIPAM 2019, 3).

29 Law n. 401, 1990.

30 Law n. 401, 199o. 
of ambassadors and consuls largely depend on personal and cultural sensitivity and other hands-on considerations. Balancing between the superior's overarching priorities and the IIC's cultural agenda requires, in some cases, a capacity to handle pressure and to shield the institute's sphere of action. In practice, constant dialogue and joint initiatives with embassies and consulates tend to guide relations in the local diplomatic mission.

Italy's mono-attachment model to the MFA also applies to funding, with an endowment assigned to each IIC from the MFA's annual budget. A separate funding chapter of this budget covers attachés' salaries and abroad allowances. On top of this annual allocation, IICs can receive additional financial resources through sponsorships, projects with local partners, and language courses. For the latter, IICs can organise them only on the condition that they are not loss making. ${ }^{31}$ Finally, inter-ministerial initiatives may provide additional funding opportunities. An example comes from the creation of the 'Fund enhancing the promotion of the Italian culture and language abroad'. The fund provided an additional financial support of about 150 million euros spread over a period of four years (2017-2020). The financial envelope was assigned to the MFA, the $\mathrm{MoC}$ and the Ministry of Education, ${ }^{32}$ and supported, inter alia, the implementation of the 2016 promotion plan called 'Vivere all'Italiana' (Living the Italian way of life), initiated by the MFA in co-operation with the MoC, Società Dante Alighieri, ${ }^{33}$ and other actors of Italy's cultural diplomacy. ${ }^{34}$

While the number of joint initiatives between the MFA and the MoC, at both the central and the local levels, has increased recently, a general agreement was found during interviews that co-operation is not structural but rather ad hoc. Some attachés welcomed the current nature of the relations, warning that more structural arrangements between two administrations known to be highly bureaucratic may cause a delay to procedures.

Italy's mono-attachment model also has important implications for the definition of a cultural attaché's agenda. On the one hand, the MFA increased its programming leadership in recent years by launching a series of annual events based on different aspects of Italy's culture: the Week of Cinema, the Day of Science, the Day of Contemporary Art and the Italian Design Day, among

\footnotetext{
$31 \quad$ Ministerial Decree n. 392, 1995.

32 Decree of the President of the Council of Ministers 2017, 2.

33 The foundation of Società Dante Alighieri (Dante Alighieri Society) dates back to 1889 . The Society is a non-profit organisation seeking to promote and foster the Italian language and culture and has a network of about 80 Italian Committees and 400 International Committees. Committees offer courses of Italian language and culture and organise cultural activities. 
others. In some cases, these events are organised with the Ministry of Cultural Heritage and Activities and Tourism (Ministero per i Beni e le Attività Culturali e il Turismo, MoC) and seek to provide an umbrella to harmonise the network of the IICs' activities and to communicate a more coherent message.

At the same time, this centralised activity is coupled with an attempt to design a cultural programme that is tailored to the needs of local realities and their familiarity with Italy's culture. As actors sitting at the crossroads, cultural attachés are involved in a complex balancing act between the ministerial agenda, the diplomatic mission's goals, local actors' sensitivity and, last but not least, the expectations of Italian communities living abroad. In the words of some operators, this gives 'a stimulating liveliness' to their work and a commitment to design activities with 'a strong plurality of voices'.

At the same, implementing this rich programme requires an onerous amount of administrative and accounting work that dominates the agendas of cultural attachés. In some cases, interviewees reported spending over 80 per cent of their time on administrative procedures that regulate the life of the institutes. The problem stems primarily from the broader reality of Italian knotted bureaucracy, but long-term gaps in staffing of the institutes are also a significant matter, since they have further lengthened existing bureaucratic procedures. At the time of the interviews (May-December 2019), more than one-third of the total number of permanent positions were vacant. Since this shortage also concerns directors' posts, some cultural attachés have temporarily covered this vacancy. The hiring competition started in 2018 has partly curbed this staff shortage.

Finally, the evaluation of cultural attachés and of the broader activity of IICs takes place through a number of reporting mechanisms. On the one hand, at the end of the year each cultural attaché draws up a report of activity to be submitted to the director of the institute. ${ }^{35}$ The report includes information on the two trails of the attachés' activity: a) the implementation of the programme for the current year and $b$ ) an overview of the programming goals for next year. On the other hand, reporting documents are also embedded within the budget and the financial report submitted to the embassy or the consulate and, in a second step, to the central administration. Both the budget and the financial report include a statement of the director or the leading attaché, providing either an overview on the future or past work of the IIC. 


\subsection{The Case of the Netherlands}

Until the mid-199os, the MFA was the only authority responsible for regulating international cultural activities in the Netherlands. Despite lobbying efforts in 1967 to establish a more inclusive International Cultural Relations Coordination Committee that would involve the then Ministry of Culture, Recreation and Social Work (Ministerie van Cultuur, Recreatie en Maatschappelijk Werk), its role remained marginal, resulting in increased dissatisfaction in the arts world. ${ }^{36}$ For decades culture was instrumentalised by diplomatic agents to achieve mostly political goals; however, as the spirit of the times changed, so did perceptions about the role of the arts in diplomacy and statecraft. In 1987, a government report concluded that a division between cultural and political goals had to be made to provide clarity to the agents working on the ground. While the argument was seemingly made for practical reasons, the report boldly argued for the transfer of responsibilities to the MoC. ${ }^{37}$ The government, however, only partially adopted the recommendations of the report; while the overarching responsibility in managing the cultural diplomacy portfolio did not shift from the MFA to the MoC, the latter won the argument that the needs of the cultural sector had to be given priority over political messaging. ${ }^{38}$

At this point the rhetoric started shifting from foreign cultural policy to international cultural policy to mark this new intention. The cultural sector was advised to set up an association to manage its international activities and lobby for its position. Nevertheless, in 1995 a memorandum from the MFA finally acknowledged that a co-operative relationship between the two authorities had much more to offer. From now on, budgeting and agendasetting would be shared responsibilities with the aim to co-create outcomes. Interestingly, the change of heart took place in the years of a socialist-liberal coalition under the lead of the Dutch Labour Party. The introduction of the first joint International Cultural Policy Framework came in 1997. In a gamechanging move, the framework recognised the intrinsic value of culture as well as its extrinsic or instrumental value. ${ }^{39}$

Before the 199os the Netherlands used to employ cultural attachés (cultureel attachés) directly from the ranks of the MFA. Gradually, at the turn of the new millennium, the MFA started conceding that it would be beneficial to the overall cause if a few of the attachés were supplied by the MoC, especially in those country capitals that held the reputation of being competitive cultural hubs.

\footnotetext{
36 Pots 200o, 360 .

37 Scientific Council for Government Policy 1987.

38 Van den Brand 2015, 13.

39 Ministry of Education, Culture and Science 2002; Minnaert 2009, 10-11.
} 
While at first this had been an ad hoc decision, over the years it has proved to be an efficient method of attracting to the job well-suited candidates. Eventually the mechanism received the seal of approval to become a standard and permanent feature of the system. Now ' $[\mathrm{t}$ ] here is an agreement between the Ministry of Foreign Affairs and the Ministry of Education, Culture and Science that every time there will be a couple of positions available for candidates from the Education and Culture Ministry', an interview participant observed.

The interviews indicated that as many as half of the cultural attachés are hired through the ranks of the MFA and the other half from the MoC. In both cases, the cultural attachés are public servants with significant work experience and frequently have an educational background that lies in the arts and humanities. It is interesting that expertise on cultural matters is not solely linked to the Culture Ministry, but seasoned experts in the arts can also be found in the central service of the MFA. Posts are advertised ad hoc and civil servants are invited to apply to the position in a secondment which, as a standard, lasts for four years with the option to extend it for a year. A series of interviews at an embassy level takes place until a decision is made.

This mixed model of appointments naturally carries through budgeting, agenda-setting and evaluation. The cultural attachés work on a budget granted by the embassy through the MFA. However, they need to meet agenda goals set by both departments on a cultural and political level. It is interesting that Dutch cultural attachés act only as intermediaries between the cultural sector in the country of accreditation and the cultural sector back in the Netherlands. They facilitate co-operation and they encourage partnerships between foreign cultural institutions and creative professionals with organisations and individuals based in the Netherlands, but they are not allowed to create and lead their own projects. Consequently, they are not encouraged to seek funding from external sources to boost their operational budget. This ensures that the attachés remain impartial in their work, otherwise the risk of backtracking to already established relationships and connections to the arts sector is high.

The allocated budget is split between the goals and depending on the country the cultural goals may have more weight than the foreign policy goals and vice versa. It is, after all, known that the two organs seek different outcomes. 'We have this double system with two ministries involved. The Ministry of Education, Culture and Science is less interested in politics and focuses more on the cultural hubs compared to the Ministry of Foreign Affairs', one participant admits. As a rule, it seems that in the advanced economies the cultural dimension has more gravity whereas in countries where the society is perceived to be in transition, the political component is markedly more prominent. Until the creation of the first joint International Cultural Policy Framework in 1997 the 
two sets of goals were decided, more or less, in isolation. This has had an effect in the definition of culture espoused by the MoC and the MFA respectively. The first embraces a more focused definition of culture as the arts and letters whereas the second, with an eye to international development and crosscultural dialogue, uses a broader definition of culture as ways of life, values and norms to accommodate a wide-ranging agenda of objectives. ${ }^{40}$

In terms of evaluation, one attaché admitted that the goals have often proved difficult to meet because they prescribe and anticipate a dense net of activities to take place. 'There are several boxes in terms of aims we have to tick. We recently gave this feedback where we basically said that we need to review the system. We submit yearly reports of our activity with numbers and the Ministers themselves are obliged to give a yearly report to the Parliament.' The MFA, being responsible for the strategic and political remit of the international cultural policy plan, evaluates the work at an embassy level. The $\mathrm{MoC}$, as the agent distributing cultural grants, assesses the work from a cultural policy perspective. ${ }^{41}$ In terms of how hierarchical relations take shape, it appears that the embassy retains the first line of management. Interestingly, the attachés are still situated closer to their sending department than to their peer group as observed. In fact, Gubbels has indicated that the relationship between the two departments has often looked like a tribal struggle in the past. ${ }^{42}$ Indeed, the attachés seem to be entrenched in their own professional territories and the networked relationships they form with their fellow cultural attachés come as secondary.

\subsection{The Case of Sweden}

For much of the 2oth century, responsibility for international cultural activities in Sweden fell on several diverse policy areas such as education, foreign affairs, development aid policy and trade relations. ${ }^{43}$ This fragmentation between markedly varied fields was caused more by the absence of a dedicated support system to co-ordinate international cultural activities than a genuine will to mainstream culture and the arts. The first cultural policy framework in the country, introduced in 1974, included provisions on the internationalisation of the cultural policy agenda by encouraging cultural institutions to invest in international projects although admittedly 'going global' was not a

\footnotetext{
$40 \quad$ MFA 2001.

41 MFA and Ministry of Education, Culture and Science 2008.

42 Gubbels 2009.

43 MoC 2003.
} 
key preoccupation of the legislators. ${ }^{44}$ The situation would remain unchanged until the 199os when political circumstances forced many actors to recalibrate their scope. The collapse of the Soviet Union and, subsequently, the march into freedom of the Baltic states, redrew Sweden's map of interests. The country's accession to the EU in 1995 also had a knock-on effect in rearranging domestic priorities and accelerating the push towards internationalisation. Soon the MFA installed cultural attachés in the Baltic region (Tallinn, Riga, Vilnius), in addition to the ones that already existed in developed countries, and an attaché with a cultural and audio-visual remit was appointed to represent Sweden in the EU. 45

Until the early 2000 s the body of the cultural attachés (or counsellors for cultural affairs - kulturråden) was still coordinated by the MFA. In 2003, it was decided by the social democratic government in office that the MoC would take over the responsibility of this special arm of the foreign service in an arrangement that still continues today. This did not signal a fracture in the relationship between the two state organs or the definitive departure of the MFA from the affair. The MFA and the MoC take a combined approach in managing the body of the cultural attachés in a well thought-out 'balancing act'. The $\mathrm{MoC}$ has the legal responsibility of co-ordination but it co-operates with the MFA in a number of operational areas. Although there was initially scepticism in the ranks of the MFA on the new structural arrangements, the model of cooperation has been cemented and refined over the years. As one interviewee noted: 'The Ministry of Foreign Affairs at first didn't like the idea of having to share the legal responsibility with the Ministry of Culture, but it was a decision that came from the top'. Much seems to have changed today since those early days as the cultural attachés and the representatives from the two ministries all find this symbiotic model to be a natural step forward. Today, both the MoC and the MFA underline the importance of two-way communication in order to build an inclusive environment for the cultural attachés that accommodates the strategic intentions of both actors.

In terms of appointments, each post is advertised separately on a contractual basis of three years, which may be extended to a maximum of five years. The roles are open to anyone; however, experienced professionals from the broader cultural sector, who have a track record of collaborating with foreign partners, are particularly encouraged to apply. The hiring process may be organised by the MoC, although representatives from the MFA and the embassy in search

44 Government of Sweden 1974.

45 Government of Sweden 2009. 
of a suitable candidate are invited to sit on interview panels. This is an important aspect of the co-operation model since it is the diplomatic mission which, in the end, will host the newly hired. Sweden maintains a small number of cultural attachés (at present there are nine posts) placed strategically in countries which not only present bilateral interest for Sweden, but also have a solid international standing in terms of their cultural, political and economic significance. While the location of the posts is reviewed frequently on an evidential basis, Sweden has a long-term presence in France, the United Kingdom, Germany, the United States, Russia, China, Turkey and Belgium (this last post is linked to monitoring developments and changes in EU cultural policy). The newest addition in the group is the post in South Africa which allows Sweden for the first time to be represented in the African continent.

In terms of hierarchy, unsurprisingly the attachés remain closer to the MoC than the MFA as a consequence of being hired directly from the arts sector. This results in increased interactions with the rest of the attachés since perceptions about the nature of the work are shared and the career path that awaits most of them afterwards is somewhat similar. With few exceptions, the attachés are re-absorbed by the Swedish cultural sector, usually in positions that involve managing international cultural co-operation projects.

The intricate and delicate hiring arrangements are well reflected in the financing model of each post. The MoC covers the subsistence costs of the cultural attachés abroad but the resources to organise projects are granted by the MFA through the embassy budget. Unlike their Dutch colleagues, the Swedish attachés are encouraged to seek external funding to top up their operations budget. The grant they receive through the embassy budget differs from case to case and depends not only on the size of the country but also on how the diplomatic mission has evolved institutionally over time. For instance, there are cases where the cultural post is part of the public diplomacy team and, therefore, the budget is split between the two portfolios.

The mixed funding model observed above shapes both agenda-setting and evaluation. The strategic agenda has been the interview theme which yielded the most interesting insights. The cultural attachés have guidelines jointly approved by the MoC and the MFA which resonate with the overall cultural and foreign policy priorities of Sweden. However, the MoC does not set priority areas to the attachés according to their location. Each agent decides what their toolkit will involve based on local demand, and this usually builds on the attaché's previous professional experience. Selecting to work with specific art forms (dance, theatre, music, literature, visual arts, etc.) is a great challenge for agents operating abroad. Even if a selection is made by the attaché on the 
art form(s), the country as a whole has various needs across its territory and, therefore, working with more art forms may provide access to a larger and more varied audience. This has been a perennial issue in cultural diplomacy, so it is perhaps a natural consequence that, while there are broader administrative frameworks which the attachés should follow, both government departments (MFA, MoC) accord to the cultural attachés relative freedom to experiment and tailor their approach. Indeed, loosely defined goals allow for better localisation and adaptation of projects. The interviews revealed that the embassy is most likely to request a tactical alignment with the embassy strategy plan; however, this is not a rule and depends on the mission and the ambassador. Setting the agenda proves to be an area of delicate balance for the two ministries which seem to be tiptoeing carefully in this zone of shared jurisdiction.

Moving on to evaluation, there was general consensus among the participants that impact evaluation is not a well-developed area. Routine reports are submitted to the embassy and the ministerial departments in Stockholm, but these mostly focus around financial auditing and 'measuring numbers' to illustrate the arguments brought forward rather than understanding impact. While nearly all the attachés acknowledged that the bureaucracy that this profession entails tends to be a burden, they also admitted that benchmark assessment to evaluate their work did not exist. As one interviewee admitted: 'There is no way we can tell objectively whether someone has been a good or a bad cultural attaché.' This absence of assessment criteria may be partly justified as benchmarking tends to ignore local needs and, therefore, mutes the reasons why a project was developed and executed in a certain way.

The carefully curated conditions described in this section demonstrate that the Swedish cultural attachés enjoy relative autonomy from the political remit of the foreign service. Their political independence is seen as an asset that needs to be safeguarded. The participants noted that the political independence of the cultural attachés may also work as significant reputational capital for Sweden. While the country already has a good reputation abroad due to its generous domestic welfare policies and its status as a major donor country channelling considerable funds through development assistance programmes, its ability to allow its agents to operate freely is highly valued by partners in countries where artistic freedom is not granted, for example in Russia and China. The emphasis on autonomy is also manifested linguistically. The Swedish cultural attachés use terms such as 'relationship-building' and 'international cultural policy', avoiding the term 'cultural diplomacy' altogether since, according to their view, the term is still linked to the Cold War period and bears connotations of Soviet propaganda and misinformation. Indeed, the literature endorses this remark. The term was first used in the 
English-speaking world in the period of the Cold War to denote manipulative actions orchestrated by governments to offset aggressive behaviour shown on the international scene. ${ }^{46}$

\section{5}

\section{Discussion}

Based on the interview findings, we argue that Sweden and the Netherlands have a symbiotic model where the MFA co-operates with the MoC for the appointment, strategic conditioning and overall management of the body of cultural attachés. Italy presents an entirely different case; here the network of the IICs is linked exclusively to the embassies and the MFA. While interministerial co-operation has been on the rise, it follows an ad hoc rationale and only takes place in specific projects.

Considering the above, we can distinguish between two distinct models:

Mono-attachment model

Case study 1: Attachment to the Ministry of Foreign Affairs.

\section{Pluri-attachment model}

Case study 2: Attachment to the Ministry of Foreign Affairs and the Ministry of Education, Culture and Science.

Case study 3: Attachment to the Ministry of Culture and the Ministry of Foreign Affairs.

It is interesting that both Sweden and the Netherlands started out with the same structural arrangements. The arm of the cultural attachés was virtually an extension of the foreign service. However, at the turn of the millenniumand incidentally during the office of socialist governments in both countriesit was felt that the system had to be reviewed. This is a perfect example of policy convergence. Neither Sweden nor the Netherlands have emulated each other's paradigm; yet, through trial and error they arrived at the same policy solution. This is an interesting observation for this model, which appears to be guided by the concept of utility. Albeit presenting slight variations, the 'pluriattachment' model is based upon the same principles of co-operation to maximise what is perceived to be mutual gains. This open, co-operative approach to policymaking permeates a range of other functions and is characteristic of the

46 Barghoorn 196o, 10. 
civil service of the two countries in what is known in literature as 'collaborative governance', 'networked governance' or 'rhizomatic governance.'47

Italy's 'mono-attachment' model seems at first to endorse Hocking's view that the MFA operates as a gatekeeper clinging onto its jurisdiction. ${ }^{48}$ However, the detailed analysis of the Italian case revealed that autonomy is a spectrum and that despite appearances, agents within the network can shape decisively their own agendas based on challenges and opportunities arising from the field. Like Carta and Badillo's analysis of the cultural diplomacy structures of France, Germany, Spain and the UK, our findings on Italy show that its model does not seem to be entirely guided by the central authorities. ${ }^{49}$

While we hope that the brief country profiles shared above have painted a thorough picture of the cultural attachés' relative position within the government system, they have focused nonetheless on the more prosaic elements of their work life. From appointments and funding to evaluation, this article has offered an insider's view of their relationship with other agents of power such as embassies and ministries. Despite the commonalities observed across these systems, most centring upon the attachés' work routines as well as the irrefutable truth that all of them found that the job entailed too much bureaucracy, stark differences were also noted.

Italy has by far the highest number of cultural attachés $(<140)$ compared with Sweden $(<10)$ and the Netherlands $(<15)$. This is perhaps a result deriving from the fact that the Italian MFA historically maintains a high number of cultural institutes abroad, a legacy network from a time long gone, 'the age of empires' as British historian Eric Hobsbawm would remark. Contrary to common neoliberal rhetoric which sees traditional communications shifting towards digital engagement, the model of physical representation still works well, at least for the most part, especially in those countries where the biggest and most popular cultural institutes such as the British Council and the Institut français maintain a physical presence.

By contrast, Sweden and the Netherlands, having built piecemeal their international presence, have chosen to place their agents within select embassies worldwide, hence, the lower numbers of representatives. Very often the cultural attachés will be found in the embassies of major capitals. From New York to London, Paris and Tokyo, the two countries have developed a flexible model that allows them to read the environment and install attachés where new state interests arise. This is a model that economises resources and has persistently avoided committing large sums to the maintenance of physical sites.

49 Carta and Badillo 2020, 8o-81. 
In terms of project management and evaluation, while all attachés are posted abroad with the same goal to promote their countries, localising the mandate is a necessary condition. Admittedly, the priorities may vary immensely often within one country alone. The greater the size of a country, the more diverse its population is and, consequently, the more wide-reaching the agenda of the attaché should be. It is perhaps reasonable then why none of the three cases presented us with a fixed evaluation framework to assess their outputs. Striking a balance between evaluating outcomes and weighing these against the context they were produced is an enormous challenge in this field.

Last, focusing on a subject of a more conceptual nature, it appears that the co-operative model of the Netherlands and Sweden is strongly linked to an engagement with a wider portfolio of thematic priorities where the arts and culture often operate as vehicles to discuss broader societal issues such as human rights, environmental protection, gender equality and democracy next to the more traditional 'arts and crafts' agenda. By contrast, the Italian model sees culture as the expression of human creativity and, therefore, places emphasis on the arts, literature and cultural heritage. It is crucial to note that there is no right or wrong paradigm here in the sense that there is no loss of value by practising either one of the two approaches. Therefore, the interpretation of culture through either its broad or narrow sense works equally well and depends on the context of each project and the needs of each audience.

This article has focused on the subject of cultural attachés in an attempt to assess their relative position within the government apparatus. To achieve this, it has examined their relations with the diplomatic missions, the MFA and the MoC by comparing the practices of three countries (Italy, the Netherlands and Sweden). As a result of the analysis, the authors created a typology of two distinct models which describe the interactions between the attachés and other state agents of their immediate regulatory environment. In the 'monoattachment model', a prime example of which is Italy, the cultural attachés are exclusively linked to the MFA. Formal co-operation with other ministerial authorities occurs ad hoc and is usually project-based. This model is not entirely guided by central authorities and the operational and financial autonomy of IICs allow them to design programmes tailored to local needs. In the 'pluri-attachment model', represented in this study by Sweden and the Netherlands, there is shared agreement that a co-operative approach to cultural diplomacy is beneficial to the overall cause. The MFA and the MoC join forces to create common framework conditions for the cultural attachés which 
cover areas such as budgeting and strategic planning. It is interesting that while both country examples share common principles and qualities which lead us to register them into the same category, there are different arrangements even within the pluri-attachment model. In Sweden it is the MoC that is in charge of co-ordinating the relationship whereas in the Netherlands it is the MFA that oversees the affair.

Interestingly, the above structural arrangements have a knock-on effect on perceptions. Closer association to the MFA is linked to an understanding of cultural diplomacy more akin to realpolitik although the cultural attachés on the ground, engaged in their everyday reality, are aware that successful and impactful cultural work should go beyond mere display and showcasing to involve 'deep' exchanges and inclusive co-operation. In the Italian case, the autonomy of the IICs shields them from purely utilitarian visions of culture. By contrast, in the Netherlands and Sweden, the involvement of the MoC in co-setting the scene in conjunction with the MFA seems to dilute, to an extent, utilitarian perceptions about the role of culture in diplomacy, inviting a more nuanced discussion. This does not mean that the diplomatic missions worldwide accord the same importance to both areas. Depending on the country, political priorities may dictate a more realist approach. Either way, it becomes evident that the agents on the ground are by far the most important players in the equation.

It is worth noting that the two models identified above are not the only possible combinations of how the cultural attachés may be embedded in the administration of their country. The example of Australia, where the Australian Council for the Arts maintains its own network of agents working to support artistic exchanges abroad, shows that ministries are not the only rightful agents to pursue cultural affairs beyond the domestic frontier. Switzerland also poses a compelling case; as the country is federally organised in cantons, the various states retain de jure the right to work on international cultural projects. Yet most public spending on cultural promotion abroad is done by Pro Helvetia (the Swiss Arts Council), which is directly mandated by the parliament. These examples illustrate the variety of possible arrangements and reveal the need for more research to determine the impact these organisational systems have on the practice of cultural diplomacy.

\section{Bibliography}

Ang, Ien, Yudhishthir Raj Isar and Phillip Mar. 'Cultural Diplomacy: Beyond the National Interest?' International Journal of Cultural Policy 21 (4) (2015), 365-381. 
Angell, Svein Ivar. 'The Office for Cultural Relations: Representing Norway in the Post-War Period'. In Histories of Public Diplomacy and Nation Branding in the Nordic and Baltic Countries, ed. Jan Melissen (Leiden: Brill Nijhoff, 2015), 79-101.

Ansell, Chris and Alison Gash. 'Collaborative Governance in Theory and Practice.' Journal of Public Administration Research and Theory 18 (4) (2008), 543-571.

Barghoorn, Frederick. The Soviet Cultural Offensive (Princeton: Princeton University Press, 1960).

Bjola, Corneliu and Marcus Kornprobst. Understanding International Diplomacy: Theory, Practice and Ethics (London: Routledge, 2018).

British Council. Art, Cultural Relations and Soft Power: Developing an Evidence Base (London, 2017). https://www.britishcouncil.org/sites/default/files/arts_cultural_re lations_final_report_for_british_council.pdf.

Bryson, John M., Barbara C. Crosby and Melissa Middleton Stone. 'The Design and Implementation of Cross-Sector Collaborations: Propositions from the Literature'. Public Administration Review 66 (2006), 44-55.

Carta, Caterina and Ángel Badillo. 'National Ways to Cultural Diplomacy in Europe:The Case for Institutional Comparison'. In Cultural Diplomacy in Europe, eds. Caterina Carta and Richard Higgott (Cham: Palgrave Macmillan, 2020), 63-88.

Carta, Caterina and Richard Higgott, eds. Cultural Diplomacy in Europe: Between the Domestic and the International (Cham: Palgrave Macmillan, 2020).

Commissione RIPAM. Resolution (Rome: Delibera, 2019). http://riqualificazione .formez.it/sites/all/files/delibera_maeci_orali.pdf.

Constantinou, Costas, Noé Cornago and Fiona McConnell. 'Transprofessional Diplomacy'. Brill Research Perspectives in Diplomacy and Foreign Policy 1 (4) (2016), 1-66.

Cull, Nicholas J. 'Public Diplomacy before Gullion: The Evolution of a Phrase'. In Routledge Handbook of Public Diplomacy, eds. Nancy Snow and Nicholas J. Cull (London: Routledge, 2009), 19-22.

Cummings, Milton. Cultural Diplomacy and the United States Government: A Survey (Washington, DC: Center for Arts and Culture, 2003).

Decree of the President of the Council of Ministers. Decree of 6 July 2017 on the Individuazione degli Interventi da Finanziare con il Fondo per il Potenziamento della Cultura e della Lingua Italiana all'Estero', set up pursuant to Article 1, paragraph 587 , of the Law 11 December 2016, n. $23^{2}$ (Law of 2017 Financial Statements) [Identification of the Interventions to be Financed with the Fund Enhancing the Promotion of the Italian Culture and Language Abroad].

Donaldson, Frances. The British Council: The First Fifty Years (London: Vintage, 1984).

Embree, John. 'Some Problems of an American Cultural Officer in Asia'. American Anthropologist 51 (1) (1949), 155-158.

European Commission and High Representative. 'Towards an EU strategy for International Cultural Relations'. Joint Communication to the European Parliament 
and the Council, 2016. https://eur-lex.europa.eu/legal-content/EN/TXT/?uri=JOIN \%3A2016\%3A29\%3AFIN.

European Parliament. European Cultural Institutes Abroad. Committee on Culture and Education (Brussels: European Parliament, 2016). https://www.europarl.europa.eu/ RegData/etudes/sTUd/2016/563418/IPOL_STU(2016)563418_EN.pdf

Ferri, Carla. La promozione culturale del Ministero degli Affari Esteri [The cultural promotion of the Ministry of Foreign Affairs] (Rome: Anicia, 2012).

Flick, Uwe. 'Triangulation in Qualitative Research'. In A Companion to Qualitative Research, eds. Uwe Flick, Ernst von Kardoff and Ines Steinke (London: SAGE Publications, 2004), 178-183.

Gould-Davies, Nigel. 'The Logic of Soviet Cultural Diplomacy'. Diplomatic History 27 (2) (2003), 193-214.

Government of Sweden. Proposition angående den Statliga Kulturpolitiken [Proposition 1974:28. Proposition on State Cultural Policy] (Stockholm: State Publisher, 1974).

Government of Sweden. Tid för kultur 2009/10:3 [Time for culture] (Stockholm, 2009). Gray, Clive and Melvin Wingfield. 'Are Governmental Culture Departments Important? An Empirical Investigation'. International Journal of Cultural Policy 17 (5) (2011) $590-604$.

Gubbels, Truus. 'Van Stammenstrijd naar Culturele Diplomatie' [From Tribal Struggle to Cultural Diplomacy]. Boekman 21 (80) (2009), 16-20.

Helly, Damien and Domenico Valenza. EU International Cultural Relations since 2016: Progress Report. Culture Solutions Europe, 2020. https://www.culturesolutions.eu/ wp-content/uploads/2020/04/CS-BRIEF2.pdf.

Hocking, Brian, ed. Foreign Ministries: Change and Adaptation (London: Routledge, 1999).

Jablonski,John. 'The RoadTaken:Reflections of a SometimeCultural Attaché.'Hungarian Journal of English and American Studies 8 (2) (2002), 153-165.

Kizlari, Dimitra. 'The Rise of Rhizomatic Cultural Policies'. International Journal of Public Administration 43 (3) (2020), 253-261.

Kizlari, Dimitra and Kalliopi Fouseki. 'The Mechanics of Cultural Diplomacy: A Comparative Case Study Analysis from the European Context'. Journal of Arts Management, Law, and Society 48 (2) (2018), 133-147.

Law n. 401. Riforma degli Istituti Italiani di Cultura e Interventi per la Promozione della Cultura e della Lingua Italiane all'Estero. [Reform of the Italian Cultural Institutes and Interventions for the Promotion of Italian Culture and Language Abroad]. 22 December 199 o.

Law n. 2179. Disposizioni per la Creazione di Istituti di Cultura Italiana all'Estero [Provisions for the Creation of Italian Cultural Institutes Abroad]. 19 December 1926.

McMurry, Ruth Emily. 'Foreign Government Programs of Cultural Relations'. Annals of the American Academy of Political and Social Science 235 (1) (1944), 54-61. 
MAEci (Ministero degli Affari Esteri e della Cooperazione Internazionale). (2019). 'Vivere all'Italiana' [Living the Italian Way of Life]. https://www.esteri.it/mae/it/ politica_estera/promozione-integrata-del-sistema/vivere-all-italiana.html.

Mangset, Per. 'Cultural Divisions in International Cultural Co-operation'. International Journal of Cultural Policy 4 (1) (1997), 85-106.

Mark, Simon. A Greater Role for Cultural Diplomacy (Clingendael: Netherlands Institute of International Relations, 2009).

Ministerial Decree n. 392. Decreto Ministeriale 27 Aprile 1995, n. 392. Regolamento recante norme sull'Organizzazione, il Funzionamento e la Gestione Finanziaria ed Economico-Patrimoniale degli Istituti Italiani di Cultura all'Estero. [Regulation for the Organization, Operation and Financial and Economic-Patrimonial Management of Italian Cultural Institutes Abroad] 27 April 1995.

MoC (Ministry of Culture). Internationella kulturutredningen SOU 2003:121 [International Cultural Inquiry] (Stockholm, 2003).

Ministry of Education, Culture and Science. Cultuurbeleid in Nederland [Cultural Policy in the Netherlands] (The Hague: State Publisher, 2002).

MFA (Ministry of Foreign Affairs). The Art of International Cultural Policy: Evaluation 1997-200o [De Kunst van het Internationaal Cultuurbeleid. Evaluatie 1997-200o]. Development Cooperation Inspectorate and Policy Evaluation (The Hague: State Publisher, 2001).

MFA (Ministry of Foreign Affairs) and Ministry of Education, Culture and Science. Boundless Art [Grenzeloze Kunst] (The Hague: State Publisher, 2008).

Minnaert, Toine. 'Drang naar Samenhang. Het Internationaal Cultuurbeleid van Nederland' [Urge for Cohesion: The International Cultural Policy of the Netherlands]. Boekman 21 (80) (2009), 6-13.

Minnaert, Toine. 'Footprint or Fingerprint: International Cultural Policy as Identity Policy'. International Journal of Cultural Policy 20 (1) (2014), 99-113.

Noy, Chaim. 'Sampling Knowledge: The Hermeneutics of Snowball Sampling in Qualitative Research'. International Journal of Social Research Methodology 11 (4) (2008), 327-344.

Nye, Joseph. 'Soft Power'. Foreign Policy 8o (1990), 153-171.

Pamment, James. 'What Became of the New Public Diplomacy? Recent Developments in British, US and Swedish Public Diplomacy Policy and Evaluation Methods'. The Hague Journal of Diplomacy 7 (3) (2012), 313-336.

Paschalidis, Gregory. 'Exporting National Culture: Histories of Cultural Institutes Abroad'. International Journal of Cultural Policy 15 (3) (2009), 275-289.

Pots, Roel. Cultuur, Koningen en Democraten:Overheid en Cultuur in Nederland [Culture, Kings and Democrats: Government and Culture in the Netherlands] (Amsterdam: University of Amsterdam, 2000). https://pure.uva.nl/ws/files/3074231/11619_UBA o02000048_o1.pdf. 
Rivera, Tim. Distinguishing Cultural Relations from Cultural Diplomacy: The British Council's Relationship with Her Majesty's Government (Los Angeles: usc Center on Public Diplomacy at the Annenberg School, 2015).

Schunz, Simon and Riccardo Trobbiani. 'Diversity without Unity: The European Union's Cultural Diplomacy vis-a-vis the United States'. European Foreign Affairs Review 24 (2019), 43-62.

Scientific Council for Government Policy. Cultuur zonder Grenzen [Culture without Borders] (The Hague: State Publisher, 1987).

Udovič, Boštjan and Ana Podgornik. 'Cultural Diplomacy of Slavic European Union Member States: A Cross-Country Analysis'. Baltic Journal of European Studies 6 (2) (2016), 117-136.

Valenza, Domenico. 'A Crisis or a Turning Point? EU Cultural Relations with Russia after Crimea'. In Principled Pragmatism in Practice - The EU's Policy towards Russia after Crimea, eds. Fabienne Bossuyt and Peter Van Elsuwege (Leiden: Brill, 2021), 332-351.

Van den Brand, Coen. 'Gefragmenteerd Internationaal Cultuurbeleid. Een Analyse van Parlementaire Debatten Begin Jaren Negentig.' [Fragmented International Cultural Policy. An Analysis of Parliamentary Debates in the Early 199os]. Bachelor eindwerkstuk Kunstbeleid en Management, (2015). https://dspace.library.uu.nl/ bitstream/handle/1874/324627/15-10-28\%2oBachelor\%2oeindwerkstuk\%2O Coen\%2ovan\%2oden\%2oBrand.pdf?sequence=2\&isAllowed $=y$.

Wyszomirski, Margaret, Christopher Burgess and Catherine Peila. International Cultural Relations: A Multi-Country Comparison (Columbus: Ohio State University, 2003).

Yin, Robert. Case Study Research: Design and Methods (Thousand Oaks, CA: SAGE Publications, 2014).

\section{Appendix}

TABLE 1 Interviews per country

Country No of interviews

\begin{tabular}{lr} 
Italy & 8 \\
Netherlands & 8 \\
Sweden & 10 \\
\hline
\end{tabular}


TABLE 2 Typical questions asked during the interviews

Research themes:

A. Educational/Professional background

B. Employment conditions

C. Operations

D. Discourses and perceptions

1] What is your background in? (A)

2] Have you attended specific training to undertake your duties as a cultural attaché? If so, what kind of training did you receive and who provided the courses (private organisations, state institutes, academics, freelance practitioners, etc.)? (A)

3] What kind of skills do you think a cultural attaché needs? (A)

4] How long are you contracted for? (B)

5] Was there a national call or were you appointed ad hoc to this position? (B)

6] Which Ministry is formally your employer and does your direct supervisor belong to the same Ministry? (B)

7] What are the areas of collaboration between the Ministry of Foreign Affairs and the Ministry of Culture in your field of work? (C)

8] Where does the funding you have for cultural projects come from? (C)

9] How does a day in the office look like for you? (C)

10] Where do you report your activity? (C)

11] What are the interests of your home country in (country of accreditation)? (C)

12] Do you locate a difference between the terms 'cultural diplomacy' and 'cultural relations'? (D)

13] Is the cultural unit in the embassy part of the public diplomacy team? (D)

14] Do you think the post of the cultural attaché is gaining popularity amongst diplomats? (D)

15] Do you have any suggestions on how to rationalise the current system regarding your work? (D)

\section{Dimitra Kizlari}

is a researcher and practitioner with a focus on culture and the creative industries. She holds a PhD from University College London in which she compared the policies and practices of six European countries on cultural diplomacy, analysing the work of their national cultural institutes. She is guest lecturing at UCL School of Anthropology on Soft Power and Diplomacy and is also working as an expert evaluator for the European Commission in the framework of the 'Creative Europe' programme. 


\section{Domenico Valenza}

is a policy analyst in EU affairs and a researcher and lecturer in cultural policy and international cultural relations. He is currently a PhD Fellow at the United Nations University and Ghent University, and a Visiting Lecturer at Maastricht University. His area of expertise includes the Eu's external action, Russia's foreign policy, cultural diplomacy and relations, and strategic communication. Between 2016 and 2018 he worked at the College of Europe, Bruges, as a Senior Academic Assistant. 